\title{
Developing a FinTech Ecosystem in Vietnam: Opportunities and Challenges for Startups
}

\author{
Van Thien Hao* \\ Quang Trung University, Dao Tan Str.,327, 590000 Quy Nhon city, Vietnam
}

\begin{abstract}
In the article, the author has analyzed the current situation of fintech market development and Vietnam's startup ecosystem in recent years. The research results show that, in the past 3 years, the number of fintech companies in Vietnam has nearly quadrupled, the market value in 2020 is estimated at 9 billion USD. With $72 \%$ of adults using smartphones, nearly $64 \%$ of the population using the Internet, along with the young generation of technology-savvy, the explosion of e-commerce and the support of the Government, Vietnam is a potential market for implementing tech startup models. Opportunities and challenges for fintech startups in Vietnam have been discussed by the author, from which solutions to develop fintech ecosystems are proposed in the upcoming time.
\end{abstract}

\section{Introduction}

Statista's research (2019) [11] shows that in the world there are more than 10,000 Fintech companies competing with traditional banks in everything from payments, fundraising, lending, forex trading and consulting. invest. In Vietnam, Fintech has gained great attention. They mainly focus on the areas of: payments, loans/deposits and other mixed services. The revenue of the Fintech sector in Vietnam is forecast to reach about 9 billion USD by 2020, when many products are strongly increasing in price, especially in mobile payment, Internet and e-wallets. However, compared to other countries in the region such as Malaysia, China, Singapore and other countries, Fintech in Vietnam is still very limited in terms of policy mechanisms, quantity, scope of activities and many other factors.

According Simon Kemp and Kepios [15], 72\% of adults (population over 15 years old) in Vietnam use a smart phone. Meanwhile, according to Statistic, the number of smartphone users in Vietnam in 2018 \& 2019 reached 32.43 and 43.7 million, respectively, and continues to increase rapidly year by year. Vietnam currently has 64 million Internet users (of which 61.73 million people access by mobile devices, accounting for $96 \%$ of Internet users and nearly $64 \%$ of Vietnam's population), ranking 6th in Asia-Pacific Ocean and 13th in the world (according to Internet World Statistics). In addition, with the young people's understanding of information technology, the explosion of e-commerce, the proportion of people with low bank accounts... are favorable factors to develop Fintech-based Finance - Banking services in Vietnam.

\footnotetext{
*Corresponding author: vthao@qtu.edu.vn
} 


\section{Fintech Ecosystem and Startups in Vietnam}

Over the past few years, Vietnam is gradually closing the gap with the two leading startup hubs in the region: Indonesia and Singapore. One of Vietnam's advantages include its large population, which will reach 100 million people by 2030 . The majority of the population is also young, tech-savvy and heavy mobile users. The potential for developing a technology startup model in this market is very lucrative.

According to a report on investments in Vietnam startups 2019 and the first six months of 2020 by the Do Ventures fund [2], 2019 marks a record high of venture capital value in startups. Vietnam with 861 million USD, an increase of $92 \%$ compared to 2018 . This amount of capital poured into 123 investment deals, doubling over the same period. The main driver for the leap came from companies that were developing at a later stage such as Tiki, VNPay and Sendo.

Over the years, the development of technology has gradually changed the lives and behaviors of consumers. These structural changes have motivated Vietnamese startups to focus in technology investment and market expansion. The amount of investment capital and the number of domestic technology transactions have increased six-fold in just two years. Additionally, Vietnam is currently ranked second in Southeast Asia in terms of the startup ecosystem's growth rate according to Ernst \& Young (2019) [4].
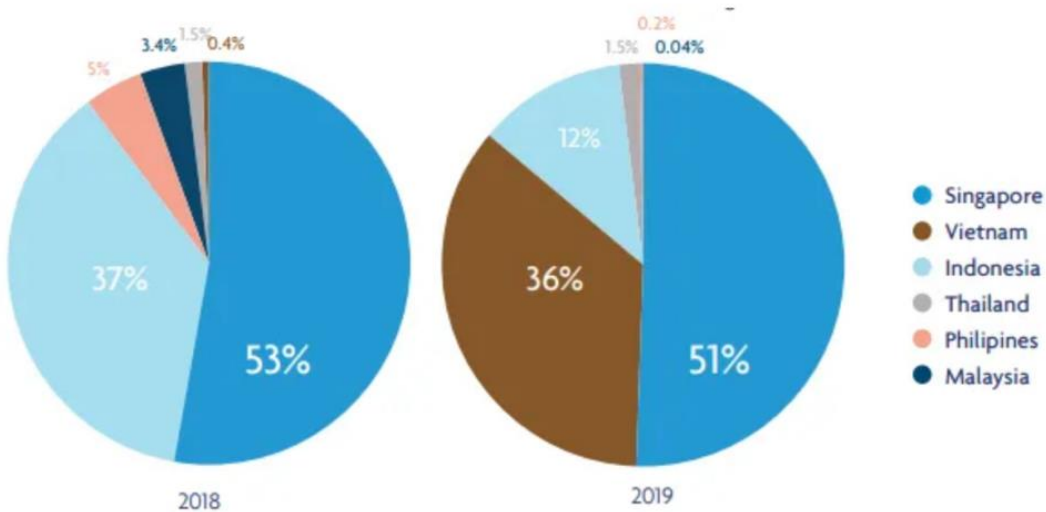

Fig. 1. The funding structure for the fintech market in Southeast Asia Do Ventures fund (2020) [2].

Besides, the impact of the digital revolution on the development of the banking industry is increasingly clear. Typical as the appearance of a variety of innovative banking products and services. New channels of distribution of banking services based on financial technology were born. In the first half of 2018, total investment in financial technology reached 31.7 billion USD for 450 successful investments [7]. This number tripled in value over the same period in 2017. In this context, the fintech segment in Vietnam is also proving its potential based on available resources. In the first half of 2019, 246 million USD was invested in startups in Vietnam, and $63 \%$ of that money went to gaming, fintech and e-commerce markets.

In recent years, many start-up incubator and acceleration programs have been opened to attract the attention of Vietnamese startups. Building a startup ecosystem is an essential need for the fintech market in Vietnam. Cooperation between the parties is important to develop the segment further. It helps create many innovations, promotes new solutions, attracts investment and qualified labor.

Fitch Rating, a financial rating agency, said that in the period of $2014-2018$, the top 11 largest Vietnamese banks have expanded their portfolio with the compound annual growth 
rate of $28 \%$, outpacing non-consumer credit's $15 \%$ [9]. It can be seen that Vietnam's consumer finance industry is entering a mature stage. This is a great opportunity for Vietnamese fintech companies to make disruption and catchup the trend of the fintech in the world.

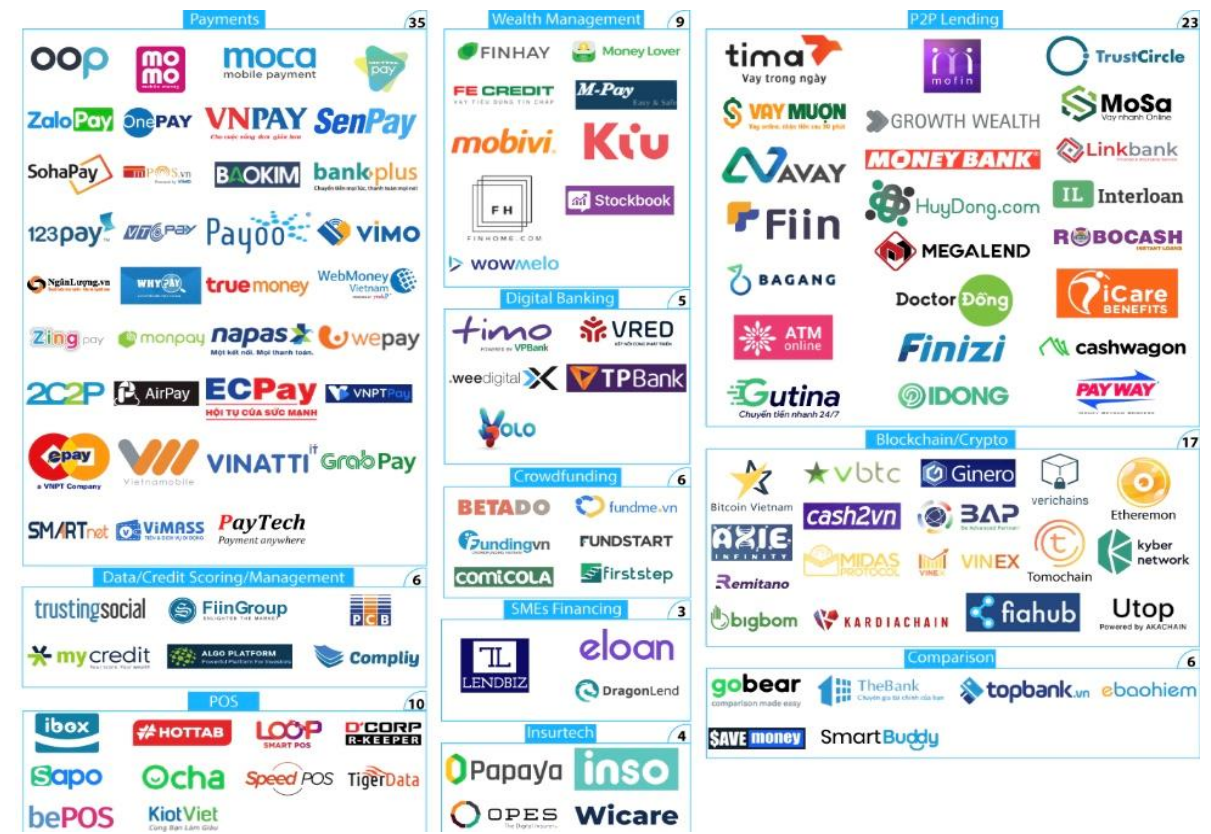

Fig. 2.Fintech Vietnam Startup Map 2019 [19]

According to research by Solidiance, a financial consulting firm fintech Vietnam, in 2017, it reached 4.4 billion USD in 2017 and is expected to increase to 7.8 billion USD in 2020, equivalent to an increase of $77 \%$ within 3 years. The development of Fintech in Vietnam is going strong, attracting 117 million USD in startup capital.

By the end of 2019, Vietnam ranked second in the ASEAN region in terms of capital to finance the Fintech market and attracted $36 \%$ of investment capital in the region, behind Singapore $(51 \%)[2,3,4]$.

In 2019, the Fintech Vietnam market achieved a strong growth in funding thanks to two big deals for VNPay payment company (300 million USD) and the C series of MoMo Pay (500 million USD). These two deals are respectively the third and biggest deal in the area [5].

The Fintech Vietnam startup ecosystem currently has about 154 operating companies which divided into main segments:

- Payment

- P2P lending (peer to peer lending)

- Digital banking

- Wealth management

- Crowdfunding

- $\quad$ Credit scoring

- Blockchain/crypto

- Comparison

- POS

- Insurtech. 
The fintech sector has a very high growth potential in Vietnam and will continue to attract funding, especially from venture capital funds. Digital payments are the top segment today. $\mathrm{P} 2 \mathrm{P}$ lending is the second largest investment segment according to CB Insights in Vietnam's Fintech market. Besides, other fintech fields such as credit scoring, asset management and personal finance are in the development stage with high growth potential.

Fintech in Vietnam mainly focuses on payment services with $47 \%$ company in the market, accounting for the highest percentage in the region. This segment always attracts many investors and becomes the general rule of countries with early developing Fintech markets. In Vietnam, companies in this segment also account for $98 \%$ of total funding for the Fintech market in 2019. There are 35 startups and platforms in the market. The notable companies and brands in this segment include M_Service, the developer of mobile payments app MoMo and one of the most well-funded fintech startups in Vietnam, Moca, a free mobile payment application for Vietnamese consumers, GrabPay, a mobile wallet integrated into Grab's app in Vietnam, and ZION, the company behind Zalo Pay, a service integrated with Vietnam's popular messaging platform Zalo that lets users link a payment card to make P2P payments, pay via NFC, QR codes, as well as purchase products and services online, mobile topups, and pay their utility bills.

$\mathrm{P} 2 \mathrm{P}$ lending (or peer-to-peer lending) is an activity that allows individuals and businesses to lend and borrow money. With an efficient structure, P2P lending can offer low interest rates and improve lending processes between lenders and borrowers. A little bit different from banks is that these fintech companies are technically not involved in lending. It is simply the connection between the lender and the borrower and collects the user's fees. This is the second largest Fintech segment in Vietnam with more than 20 startups. The outstanding companies in this segment include: Timo, a consumer financial marketplace and P2P lending platform, Growth Wealth, a P2P lending platform for small and medium-sized enterprises (SMEs) in Vietnam, as well as TrustCircle, and VayMuon.

\section{Opportunities and challenges for the fintech market in Vietnam}

In three years, from about 40 Fintech companies, this number has quadrupled to more 150 companies today. The progress of Vietnam's fintech industry occurred due to:

- Vietnam provides the necessary infrastructure for fintech services, even in remote areas;

- Vietnam has a large proportion of the highest smartphone inSoutheast Asia [12];

- Besides, the income and consumption level of Vietnamese people has been increasing in recent years;

- Currently, the government has begun to pay attention to the development of fintech. In 2018, a Steering Committee was established to help improve the industry's ecosystem. Besides, the instructions to reduce cash transactions from now to 2020 to less than $10 \%$ is also an effort to promote the cashless economy [14].

"Vietnam is going through an important period. As the key components of the digital economy begin to form," according to joint research by ESP Capital and Cento Ventures [5]. The study also said that Vietnam's digital economy would enjoy from a young and tech-savvy demographic. There would be an extra 10 million users participating in the online consumer sector by 2023. These are the factors that create momentum for many consumer finance companies to partner with the fintech scene because they are digitizing heavily.

Vietnam hidden opportunity for fintech startups

Vietnam is a young country, capable of grasping trends quickly. Which is favored by the international market. Meanwhile, Fintech operates in many different fields. This creates a great opportunity for Financial Technology in Vietnam to have a chance to grow stronger. 
The number of non-cash transactions in Vietnam is the lowest in Southeast Asia. According to a World Bank survey, the rate of non-cash transactions in Vietnam is $4.9 \%$, which is much lower than Thailand (59.7\%), Malaysia (89\%) and China (26\%). Therefore, Vietnam is a very potential market for startups in the fintech sector [9]. In order to promote the development of the fintech market in Vietnam, the Vietnamese government has many policies to encourage and support the market as well as startups in this field:

- In 2016, the government established the Nation Agency for Technology Entrepreneurship and Commercialization Development (NATEC) to provide, train, mentor, incubate businesses and provide financial support to tech startups

- Preferential policies for things for startups under certain conditions. Corporate income tax reduction for companies working in the high-tech sector or in high-tech zones (preferential tax rate: $10 \%$ for 15 years or $17 \%$ for 10 years compared to the normal tax rate of $20 \%$ )

- Focus on the STEM (science, technology and math) education model by incorporating STEM education in high school extracurricular curricula. Universities have started training in data science.

- In addition, there are a number of accelerator program in the country to support startups.

However, currently in Vietnam, there are no large-scale Fintech companies, as well as no tax incentives for angel investors and venture capitalists like some Fintech centers in the world. This has created many challenges for the growth of the fintech industry as well as for fintech startups.

Part of the reason "constraining" the development of financial technology is due to the incomplete legal framework, some macro projects, and monotonous payment regulations.

In Vietnam, there is hardly any legal framework that clearly regulates the nature of products, services, standards of products/services; Operation model, legal status, establishment and operation conditions of Fintech company; consumer protection policy with financial products, personal information security.

The government agency does not have proper awareness of the role and functions of companies in the E-payment field. Fintech is considered as an extended arm of the bank that has not been operated independently as an "individual" in the financial system. E-wallets can only be used if linked to the consumer's existing bank account.

Although Vietnam is a potential market for companies in the fintech sector, the habit of using cash as well as technology infrastructure is still limited and has not met the technological foundation. It is difficult for companies in this field to expand their market.

Human resources with expertise in finance and banking are weak, and their capacity in informatics and foreign languages is limited. Senior managers often have a lot of expertise in finance but have limited technology knowledge.

In addition, the problems of business models, management skills and mid-long-term development strategy of enterprises are almost absent. So these businesses only operate in a short time and it is very difficult to grow up and continue to develop more. At the same time, for many people, Fintech is still a novel model. So has caused a lot of confusion with investors and people involved in Fintech financial activities.

\section{Conclusions}

It can be said that Vietnam has all the necessary elements for technology startups to operate and develop. However, to be able to take advantage of the great opportunities, the startups need to have a suitable investment direction to minimize the risks brought by the challenge.In addition, to develop and nurture the fintech ecosystem, it is necessary to maintain a close coordination between the three most important elements of an ecosystem, including: 
- Business environment/accessibility market;

- Government/legal support;

- Access to capital.

The advantage of the Vietnamese market is that all three above factors have been formed. However, to remove the current barriers and difficulties, the development of the legal framework and supporting policies of the Government to develop the fintech ecosystem is very necessary. Proposed mechanisms to promote fintech start-up opportunities include:

1. Supplementing and completing mechanisms and policies for Fintech activities. The Government should study and consider building supportive policies and creating an investment environment for Fintech startups; It is necessary to soon have financing policies to support research and technology application in finance - banking and other fields; Early issue a legal framework, testing mechanism (Sandbox) for high-tech applications and especially Fintech technology in the financial and banking sectors.

2. To build national digital entrepreneurship centers and creative start-up support centers at universities. The National Digital Startup Center is a government funded and invested hub. This is a favorable environment for nurturing innovative ideas and start-ups. It also helps connect collaboration opportunities and technical support for young talent with creative ideas. There are also internship programs and exchanges to create conditions for young people to approach research practices; testing innovative solutions for technology, business models, products, services... Moreover, this is also a place to share experiences from organizations, enterprises, banks, big technology companies (bigtech) domestically and internationally for startups to make their ideas come true.

3. Center for Creative Startups at Universities. This is a place that provides facilities, infrastructure, and technology facilities for students to participate in promoting creative thinking, startup ideas. This center also helps connect creative ideas between students with faculty, successful alumni of the school, businesses, investors ... so that creative ideas become feasible. In addition, the center is also a place to support Creative Startups (set up a business; transfer technology; selling solutions and products to a business ...) for faculty and students to turn creative solutions into effective business solutions.

4. Build an ecosystem and diversify Fintech products. Fintech Ecosystem is a combination of Fintech Company with banks, finance companies, technology companies, state management agencies and client partners. Only when there is such a coordination between the parties will the conditions and the best environment for startups in the Fintech field be successful and thrive.

In addition to promoting ecosystem construction, the diversified development of Fintech products not only focuses on areas such as payment, money transfer, online lending, but Fintech needs to expand into potential applications such as financial management, online investment, personal financial consulting; fields of industry, agriculture, business, logistics, education, health care, tourism to meet the diverse needs of customers in the 4.0 revolution and the digital age.

5. Organizing digital startup forums, Fintech seminars and promoting communication activities. State management agencies need to coordinate with technology organizations and associations to regularly organize forums, seminars, seminars on entrepreneurship, fintech, digital technology to share experiences and introduce public technology, recommendations on state policies to promote digital start-ups, fintech and technology application.

The government should have a policy to support the Fintech community. The media also needs to promote activities to promote and disseminate knowledge about Fintech, introduce Fintech applications to the community of people and businesses to know the benefits that Fintech brings. At the same time, it is also important to disseminate preventive measures to limit risks in online transactions in the network environment. 


\section{References}

1. Casey Hynes, How Vietnam's Fintech Market Could Reach Nearly $\$ 8$ Billion by 2020, Forbes (2019)

2. Do Ventures fund, Vietnam Tech Investment Report 2019-H1 2020 (2020)

3. Ernst \& Young, ASEAN FinTech Census 2018 (2019)

4. Ernst \& Young, Global FinTech Adoption Index 2019 (2019)

5. ESP Capital and Cento Ventures, Vietnam Tech Investment Report (2019)

6. The future of finance is emerging: new hubs, new landscapes. Global Fintech Hub Report (2018)

7. KPMG, The Pulse of Fintech: Biannual global analysis of investment in fintech (2019)

8. A. Patwardhan. K. Schmitz, K. Singleton, Financial Inclusion in the Digital Age. International Finance, 8 (2019)

9. Shaun Turton, Vietnam Fintech sector set for 'bloodbath' competition, Nikkei Asian review (2019)

10. A. Demirguc-Kunt, L. Klapper, D. Singer, S. Ansar, J. Hess, The Global Findex Database 2017: Measuring Financial Inclusion and the Fintech Revolution (2018)

11. Le Dat Chi, Tran Hoai Nam, Journal of Science and Technology of Vietnam, 5 (2019)

12. Finch Capital, MDI Ventures and Dealroom.com, The Future of Fintech in Southeast Asia (2020)

13. Álvaro Ortiz Vidal-Abarca, Le Xia, SumedhDeorukhkar, Tomasa Rodrigo and Alfonso Ugarte, Fintech in Emerging ASEAN Trends and Prospects(2017)

14. World Bank, Vietnam's financial inclusion priorities: Expanding financial services and moving to a 'non-cash' economy (2017)

15. United Overseas Bank and the Singapore FinTech Association,FinTech in ASEAN: The Next Wave of Growth (2019)

16. H. Gimpel, D. Rau, and M. Roglinger, Electronic Markets, 28 (2018)

17. In Lee, Yong Jae Shin, Fintech, Business Horizons, 61 (2018)

18. R. Alt, R. Beck, and M.T. Smits, Electronic Markets, 28 (2018)

19. Official website of Fintech news Singapore, https://fintechnews.sg/ 